\title{
Sleep Quality and Mental Disorders and Related Factors in Pakistan
}

\section{Anum Mehmood ${ }^{1,2}$, Arif Hussain Kaleri ${ }^{1,2}$, Asif Ali Kaleri' ${ }^{3}$, Mir Muhammad Nizamani ${ }^{1,2}$, Aamir Ali Khokhar ${ }^{1,2}$, Saqib Ali Nawaz ${ }^{4, *}$, Raza Ahmad $^{4}$, Uzair Aslam Bhatti ${ }^{3,5}$, Feroz Gul Nizamani ${ }^{3}$, Raza Ali Rind ${ }^{3}$ and Muhammad Uzair Khokhar ${ }^{3}$}

'Department of Biochemistry and Molecular Biology, Hainan University, Haikou, Pakistan

${ }^{2}$ Hainan University, Life Sciences and Agricultural College, Haikou, Hainan, Pakistan ${ }^{3}$ Department of Agronomy, Sindh Agriculture University, Tando Jam, Hyderabad, Sindh, 70060, Pakistan

${ }^{4}$ College of Information Science and Technology, Hainan University, Haikou, Pakistan ${ }^{5}$ College of Geography, Nanjing Normal University, Nanjing city, Jiangsu Province, Pakistan

Article Type: Article

Article Citation: Anum Mehmood Arif Hussain Kaleri, Asif Ali Kaleri, Mir Muhammad Nizamani, Aamir Ali Khokhar, Saqib Ali Nawaz, Raza Ahmad, Uzair Aslam Bhatti, Feroz Gul Nizamani, Raza Ali Rind and Muhammad Uzair Khokhar. Sleep quality and mental disorders and related factors in Pakistan. Indian Journal of Science and Technology. 2020; 13(03), 360-370. D0l: 10.17485/ijst/2020/ v013i03/149587

Received date: March 13, 2019

Accepted date: April 2, 2019

*Author for correspondence: Saqib Ali Nawaz \$saqibsial20@ gmail.com 9 Department of Biochemistry and Molecular Biology, Hainan University, Haikou, Pakistan

\section{Abstract}

Objective: To explore the relationship between sleep quality and mental disorders and its related factors in Pakistani, and to provide a reference for the prevention and intervention of psychological disorders in various populations. Methods: The random cluster sampling method was used to stratify 15,000 healthy people in all provinces and cities. The Pakistani Sleep Disorder Scale and the Pakistani Mental Illness Prediction Scale were distributed. The data were analyzed by SPSS 18.0 and independent sample $t$-test, correlation analysis and regression analysis. Findings: The scores of personality introversion and personality shift factors in urban populations were significantly higher than those in rural populations ( $p<0.05$ or 0.01 ). The urban-rural differences in other mental health factors were not significant $(p>0.05)$. The scores of the single-child mental health factors were significantly lower for non-only children ( $p<0.01)$; the scores of various factors on the mental health of married people were significantly higher than those of unmarried people $(p<0.01)$. There was a significant positive correlation between sleep quality and mental disorders in Pakistani $(p<0.01, r$ $=0.339-0.541$ ). Daytime function (SD1), insomnia (SD2), drowsiness of the Pakistani Sleep Disorders Scale. The five factors (SD3), exercise paradoxical sleep (SD4) and non-exercise paradox sleep (SD5) all entered the regression equation of the total score of the Pakistani Mental Illness Prediction Scale $(p=0.005)$, which could explain the variation of Pakistani mental disorders $38.8 \%$. Conclusion: There 
are some differences in sleep quality and mental disorders among different demographics, and sleep quality has a certain predictive effect on mental disorders.

Keywords: Mental Disorders, Sleep Quality, Influencing Factors, Pakistani

\section{Introduction}

Symptoms of abnormal sleep and abnormal behavior during sleep are also manifestations of normal rhythmic alternation of sleep and awakening. It can be caused by a variety of factors, often related to physical illness, including sleep disorders and parasomnia. Sleep is closely related to human health. Surveys show that many people suffer from sleep disorders or sleep-related diseases, and the percentage of adults with sleep disorders is as high as 30\%. Experts point out that sleep is an extremely important physiological function to maintain human life and is essential to the human body.

Sleep is divided into two periods based on changes in electroencephalographic recordings (EEG) and eye movement, namely non-rapid eye movement (HREM) and rapid eye movement (REM). During the non-rapid eye movement phase, muscle tone is reduced, and there is no obvious eye movement [1-4]. The EEG display is slow and synchronized. When awakened during this period, you feel tired and sleepy. During the fast eye movement period, muscle tension is significantly reduced, and rapid horizontal eye movements appear. The EEG shows a state similar to that during awakening. This period of arousal, clear consciousness, no sense of burnout, and colorful dreams appear during this period. Studies have found that the tail of the brainstem has a very important relationship with sleep and is considered to be the center of sleep. Various irritating lesions at this site cause excessive sleep, while destructive lesions cause reduced sleep. In addition, it was found that the central nervous medium is involved during sleep [5-10]. Stimulation of serotoninergic neurons or injection of serotonin can produce non-rapid eye movement sleep, while serotonin antagonists give sleep reduction. With norepinephrine antagonists, sleep is reduced during fast eye movement, while sleep with norepinephrine agonists increases sleep during fast eye movement.

Figure 1 shows the detail comparison of symptoms of the disorder of sleeping. The prevention and treatment of mental disorders have become major public health issues and have received active attention from all walks of life. At present, the etiology and pathological mechanisms of mental disorders are not fully understood at home and abroad, but it is generally believed that mental disorders are the result of a combination of biological, psychological, and social factors. For example, researchers have found that schizophrenia has a clear genetic predisposition. Most patients have a family genetic history of the disease, or other personality and emotional disorders [11-13]; In addition, patients with depression, anxiety, pain, alcohol abuse, etc. Corresponding family history exists, and physiological and genetic factors play a role in it [14-17]; At the same time, individuals with family history of alcohol abuse have passivity HPA axis activity, have 


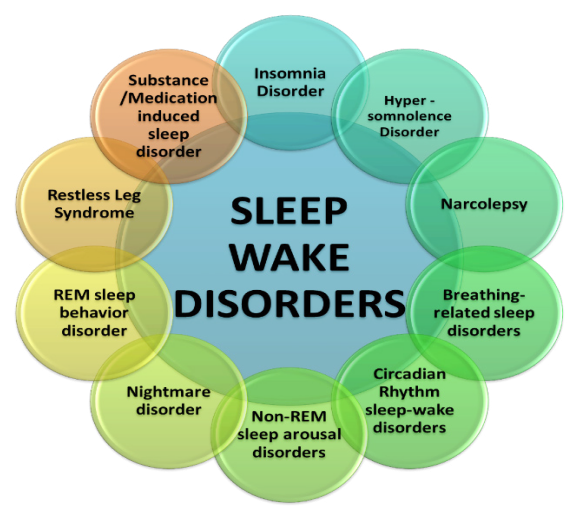

FIGURE 1. Sleeping disorder main causes and relevant factors.

less reactivity to external stress, and have anti-social increasing tendency [18]. It is [19] found that social support is related to the negative symptoms and emotional problems of patients with mental illness; social support can also improve the depression symptoms of individuals, reduce the negative trauma cognition of PTSD patients, promote the recovery of PTSD, and reduce their recurrence [20-21]; And mental health is related to factors such as life events, socioeconomic development, self-efficacy, coping style, and bad personality traits [22-23].

Sleep disorder is a clinical psychosomatic disease that can be affected by a variety of factors and has a wide-ranging effect on an individual's physical and mental health. Studies have found that sleep disorder is associated with a variety of clinical mental illnesses, such as and found that $50.3 \%$ patients with eating disorders associated with sleep disorders [24] that most of the anxiety disorders are moderately related to decreased sleep quality. Compared with patients with simple anxiety disorders, the quality of life of individuals with anxiety disorders associated with sleep disorders is more obvious, and their psychosomatic functions are more severe [25]. The severity of the symptoms of impulsive disorder is related [26]; sleep at night in children with Williams's syndrome is reduced, and their sleep problems can predict the degree of language disorders in children with Williams's syndrome [27].

From the existing research, sleep quality can predict the physical and mental health of an individual to a certain extent. However, there is still no comprehensive research on the relationship between sleep quality and mental disorders and related factors at home and abroad. This study uses the Pakistani Sleep Disorder Scale and the Pakistani Mental Illness Prediction Scale as assessment tools to examine the relationship between sleep quality and mental disorders, which are reported below.

Sleep disorders are often caused by long-term ideological contradictions or mental overload, mental labor, long-term improper combination of work and rest, and weakness after illness. After suffering from this disease, the above reasons must first be lifted and work and life readjusted. Correctly understand the nature of the disease, the onset of which occurs slowly, the course of the disease is long, often repeated, but the prognosis is good. To relieve one's suspicion of "severe illness", participation in proper physical work and physical exercise can help recover from sleep disorders. 


\section{Material and Methods}

\subsection{Research Object}

According to the data of the sixth national census (2011), according to the proportion of the population of the six administrative regions of Pakistan (1/100,000), the random cluster sampling method was used to sample 13,080 healthy people in 18 provinces and cities across the country. The Pakistani Sleep Disorder Scale and Pakistani Mental Illness Prediction Scale were issued. The test does not require filling in names to: 1) incomplete answer items; 2) continuous and random responses; 3 ) the cover-up scale score exceeds ( \pm 1.96 standard deviations) The invalid questionnaire was eliminated as a standard, and 12,260 valid samples were obtained, with an effective rate of $93.7 \%$. Among them, 6265 are males (51.1\%), 5995 are females (48.9\%); 5129 are urban (41.8\%), 7131 are rural $(58.2 \%)$; only children 6028 (49.17\%), and non-only children 6232 (50.83\%).

\subsection{Research Tools}

\subsubsection{The Pakistani Sleep Disorder Scale}

The Pakistani Sleep Disorder Scale was developed by Professor Zhang Liyi, etc. The scale includes daytime function (SD1), insomnia (SD2), drowsiness (SD3), exercise-related abnormal sleep (SD4), and non-motor-related abnormal sleep (SD5). Each of the five factors is scored at 4 levels, "never" at 0 , "occasionally" at 1, "often" at 2 and "always" at 3. The higher the score, the worse the sleep quality. The Cronbach's a coefficient of the scale is 0.822 , and the Cronbach's a coefficients of the five factors are $0.678,0.658,0.696,0.674$, and 0.395 , respectively. The retest reliability is 0.865 , and the retest correlation coefficients of each factor are $0.872,0.834,0.691,0.664$, and $0.635(p<0.01)$ [28].

\subsubsection{The Pakistani Mental IIIness Prediction Scale}

The Pakistani Mental Illness Prediction Scale was developed by Professor Zhang Liyi and others. The scale family and past history ( $\mathrm{SH} 1)$, growth experience (SH2), personality introversion (SH3), stressors (SH4), and poor mental defense (SH5) 11 factors including lack of social support (SH6), personality shift (SH7), depression (SH8), mania (SH9), neurosis (SH10), and psychosis (SH11). Two levels of scoring are used. One point is answered for "yes" and 0 points for "no". The higher the total score and the scores of the factors, the worse the mental health status and the higher the risk of mental illness. The retest correlation coefficient of the total table is 0.803 , and the retest correlation coefficient of each factor is $0.601-0.737(p<0.01)$. There was a significant correlation between the various factors of the Pakistani Mental Illness Prediction Scale, with a correlation coefficient of $0.512-0.948(p<0.01)$, a significant correlation between the total score and each factor, and a correlation coefficient of $0.673-0.961(p<0.01)$. Except for neurosis and stressor factors, the Pakistani Mental Illness Prediction Scale was significantly positively correlated with each factor score of the Pakistani Military Mental Health Scale, with correlation coefficients ranging from 0.362 to $0.618(p<0.05$ or $p<0.01)$ [29]. The reliability and validity of the above two scales are consistent with the principles of psychometrics. 


\subsection{Test Method}

The test methods are group-tested by trained professionals. All tests are informed and approved by the hospital ethics committee. Uniform guidelines were used during the test. In order to protect the privacy of the participants, the name is not required. Participants are required to fill in carefully according to their actual situation and complete it within the prescribed test time.

\subsection{Statistical Methods}

All data were statistically processed using SPSS 17.0. Descriptive statistical analysis, independent sample $t$-test, correlation analysis, and regression analysis were performed. $p$ $<0.05$ was considered statistically significant.

\section{Results}

\subsection{Analysis of Mental Disorders in Different Population Groups in Pakistan}

Take urban and rural areas, only children and marital status as grouping variables, family and past history ( $\mathrm{SH} 1)$, growth experience ( $\mathrm{SH} 2)$, personality introversion (SH3), Stressors (SH4), Poor Mental Defense (SH5), Lack of Social Support (SH6), Personality Deviation (SH7), Depression (SH8), Mania (SH9), Neurosis (SH10), Psychosis (SH11) Wait for independent sample $t$-test for test variables. The results showed that the scores of personality introversion and personality shift factors were significantly higher in urban populations than in rural populations $(p<0.05$ or 0.01 ), and there were no significant differences in other mental health factor scores between urban and rural areas $(p>0.05)$; It was significantly lower than that of non-only children $(p<0.01)$; the scores of various factors on the mental health of married persons were significantly higher than those of unmarried persons $(p<0.01)$. The results are shown in Table 1.

\subsection{Correlation Analysis of Sleep Quality and Mental Disorders in Pakistani}

The correlation analysis of Pearson's product difference between each factor of sleep disorders and each factor of mental disorders in Pakistan as shown in Figure 2. It was found that the sleep quality of Pakistani people was significantly positively related to mental disorders $(p<0.01), r=0.339-0.541$. Shown in Table 2.

\subsection{Multiple Regression Analysis of Factors Affecting Pakistani Mental Disorders}

The multiple regression analysis was performed using the Pakistani Mental Illness Prediction Scale as a total of dependent variables, and each factor of sleep disorders as 
Anum Me hmood, Arif Hussain Kaleri, Asif Ali Kaleri, Aamir Ali Khokhar, Saqib Ali Nawaz, Raza Ahmad, Uzair Aslam Bhatti, Feroz Gul Nizamani, Raza Ali Rind and Muhammad Uzair Khokhar

TABLE 1. Comparison of mental disorders among different populations in Pakistan

\begin{tabular}{|c|c|c|c|c|c|c|c|c|c|}
\hline \multirow[t]{2}{*}{ Project } & \multicolumn{2}{|c|}{ Urban and ruler } & \multirow{2}{*}{$\begin{array}{c}t \\
\text { value }\end{array}$} & \multicolumn{2}{|c|}{ Only child } & \multirow[t]{2}{*}{$t$ value } & \multicolumn{2}{|c|}{ Marriage } & \multirow[t]{2}{*}{$t$ value } \\
\hline & City & Rural & & Yes & No & & Married & $\begin{array}{l}\text { Unmar- } \\
\text { ried }\end{array}$ & \\
\hline (SH1) & $\begin{array}{l}1.88 \pm \\
2.26\end{array}$ & $\begin{array}{l}1.89 \pm \\
2.25\end{array}$ & -1.16 & $1.67 \pm 1.96$ & $1.19 \pm 2.55$ & $-9.87^{b}$ & $1.58 \pm 2.88$ & $\begin{array}{l}1.56 \pm \\
1.77\end{array}$ & $-22.32^{b}$ \\
\hline$(\mathrm{SH} 2)$ & $\begin{array}{l}2.75 \pm \\
2.82\end{array}$ & $\begin{array}{l}2.75 \pm \\
2.81\end{array}$ & 1.15 & $2.65 \pm 2.61$ & $2.85 \pm 2.97$ & $-5.53^{\mathrm{b}}$ & $2.19 \pm 2.33$ & $\begin{array}{l}2.59 \pm \\
2.67\end{array}$ & $-22.55^{\mathrm{b}}$ \\
\hline (SH3) & $\begin{array}{l}3.75 \pm \\
3.52\end{array}$ & $\begin{array}{l}3.61 \pm \\
3.37\end{array}$ & $2.19^{a}$ & $3.39 \pm 3.15$ & $3.92 \pm 3.68$ & $-7.95^{\mathrm{b}}$ & $5.77 \pm 5.18$ & $\begin{array}{l}3.29 \pm \\
2.95\end{array}$ & $-26.78^{b}$ \\
\hline (SH5) & $\begin{array}{l}3.75 \pm \\
5.76\end{array}$ & $\begin{array}{l}3.66 \pm \\
5.59\end{array}$ & 1.78 & $3.31 \pm 5.96$ & $5.12 \pm 6.29$ & $-6.65^{b}$ & $5.12 \pm 7.55$ & $\begin{array}{l}3.12 \pm \\
5.52\end{array}$ & $-27.28^{b}$ \\
\hline (SH5) & $\begin{array}{l}2.91 \pm \\
5.22\end{array}$ & $\begin{array}{l}2.92 \pm \\
5.15\end{array}$ & -1.23 & $2.71 \pm 3.72$ & $3.21 \pm 5.36$ & $-5.22^{\mathrm{b}}$ & $3.78 \pm 5.21$ & $\begin{array}{l}2.59 \pm \\
3.52\end{array}$ & $-25.22^{\mathrm{b}}$ \\
\hline (SH6) & $\begin{array}{l}2.52 \pm \\
3.28\end{array}$ & $\begin{array}{l}2.59 \pm \\
3.26\end{array}$ & -2.11 & $2.22 \pm 2.89$ & $2.88 \pm 3.55$ & $-21.77^{b}$ & $2.58 \pm 5.22$ & $\begin{array}{l}2.17 \pm \\
2.65\end{array}$ & $-22.32^{b}$ \\
\hline (SH7) & $\begin{array}{l}3.55 \pm \\
3.81\end{array}$ & $\begin{array}{l}3.32 \pm \\
3.69\end{array}$ & $3.26^{\mathrm{b}}$ & $3.31 \pm 3.27$ & $3.59 \pm 5.22$ & $-2.71^{b}$ & $3.95 \pm 5.76$ & $\begin{array}{l}3.22 \pm \\
3.18\end{array}$ & $-21.71^{b}$ \\
\hline (SH8) & $\begin{array}{l}3.97 \pm \\
5.59\end{array}$ & $\begin{array}{l}3.92 \pm \\
5.52\end{array}$ & 1.51 & $3.62 \pm 5.93$ & $5.23 \pm 5.85$ & $-5.95^{b}$ & $5.25 \pm 6.86$ & $\begin{array}{l}3.35 \pm \\
5.52\end{array}$ & $-25.77^{b}$ \\
\hline (SH9) & $\begin{array}{l}3.65 \pm \\
3.72\end{array}$ & $\begin{array}{l}3.52 \pm \\
3.67\end{array}$ & 2.71 & $3.37 \pm 3.23$ & $3.72 \pm 5.15$ & $-5.21^{\mathrm{b}}$ & $5.26 \pm 5.65$ & $\begin{array}{l}3.25 \pm \\
3.15\end{array}$ & $-22.87^{b}$ \\
\hline (SH21) & $\begin{array}{l}5.29 \pm \\
5.52\end{array}$ & $\begin{array}{l}5.21 \pm \\
5.53\end{array}$ & 1.89 & $3.92 \pm 5.95$ & $5.32 \pm 5.88$ & $-5.11^{b}$ & $5.27 \pm 6.96$ & $\begin{array}{l}3.62 \pm \\
5.52\end{array}$ & $-23.52^{b}$ \\
\hline (SH22) & $\begin{array}{l}3.22 \pm \\
5.89\end{array}$ & $\begin{array}{l}3.19 \pm \\
5.75\end{array}$ & 1.27 & $2.63 \pm 5.25$ & $3.52 \pm 6.31$ & $-7.98^{b}$ & $5.75 \pm 7.59$ & $\begin{array}{l}2.32 \pm \\
5.61\end{array}$ & $-21.35^{b}$ \\
\hline
\end{tabular}

Note: ${ }^{\mathrm{a}}$ means $p<0.05,{ }^{\mathrm{b}}$ means $p<0.01$.

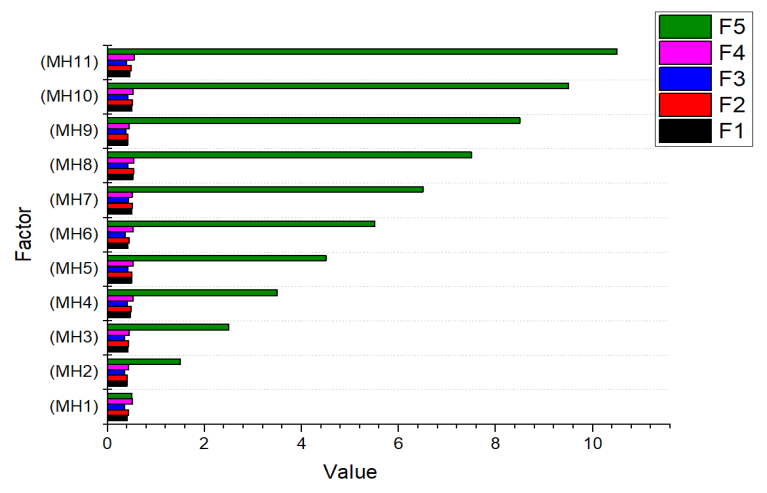

FIGURE 2. Correlation analysis of sleep quality and mental disorders in Pakistan (r).

independent variables. The results showed that the daytime function (SD1), insomnia (SD2), drowsiness (SD3), exercise abnormal sleep (SD4), and non-exercise abnormal sleep (SD5) all entered the Pakistani spirit. The regression equation of the disease prediction scale $(p=0.000)$ can explain $38.8 \%$ of the variation of mental disorders in Pakistani, see Table 3. 
TABLE 2. Correlation analysis of sleep quality and mental disorders in Pakistan ( $r$ )

\begin{tabular}{llllll}
\hline Factor & F1 & F2 & F3 & F4 & F5 \\
\hline (SH1) & 0.404 & 0.435 & 0.35 & 0.509 & 0.501 \\
(SH2) & 0.401 & 0.408 & 0.348 & 0.434 & 1.501 \\
(SH3) & 0.418 & 0.437 & 0.344 & 0.449 & 2.501 \\
(SH4) & 0.471 & 0.487 & 0.399 & 0.527 & 3.501 \\
(SH5) & 0.496 & 0.503 & 0.42 & 0.526 & 4.501 \\
(SH6) & 0.419 & 0.45 & 0.36 & 0.52 & 5.501 \\
(SH7) & 0.501 & 0.507 & 0.434 & 0.507 & 6.501 \\
(SH8) & 0.522 & 0.535 & 0.424 & 0.546 & 7.501 \\
(SH9) & 0.411 & 0.423 & 0.378 & 0.452 & 8.501 \\
(SH10) & 0.501 & 0.513 & 0.415 & 0.526 & 9.501 \\
(SH11) & 0.464 & 0.486 & 0.391 & 0.547 & 10.501 \\
\hline
\end{tabular}

TABLE 3. Multiple regression analysis of factors affecting mental disorders in Pakistan

\begin{tabular}{lllllll}
\hline $\begin{array}{l}\text { Dependent } \\
\text { variable }\end{array}$ & Independent variable & B & $\begin{array}{l}\text { Standard } \\
\text { error }\end{array}$ & $\boldsymbol{t}$ value & $\boldsymbol{p}$ value & $\boldsymbol{R}^{\mathbf{2}}$ \\
\hline Mental & Day function & 1.621 & 0.184 & 8.790 & 0.000 & 0.356 \\
disorders & Insomnia & 0.955 & 0.141 & 6.778 & 0.000 & \\
& Lethargy & 0.747 & 0.172 & 4.330 & 0.000 & \\
& Exercise paradoxical sleep & 3.356 & 0.250 & 13.352 & 0.000 & \\
& Non-exercise sleep & 3.687 & 0.204 & 18.076 & 0.000 & \\
\hline
\end{tabular}

\section{Discussion}

\subsection{Analysis of Sleep Quality and Mental Disorders}

In different demographic groups, sleep disorders can induce mental disorders such as depression and anxiety, and can affect the rehabilitation process and recurrence of mental disorders, which in turn affects the quality of life of individuals, and has received great attention from scholars from various countries [30-33]. Therefore, this study explores the relationship between Pakistani sleep quality and mental disorders and demographic variables, which is of great significance for revealing the psychopathological mechanism of mental disorders and constructing mental disorder prevention programs for different populations. At present, there is still no research on the differences in sleep status between only-children and non-only-children [34]. This study found that the only child's motor abnormal sleep and non-motor abnormal sleep factor scores were significantly lower than those of non-only children, that is, only children rarely occur. Motor and nonmotor abnormal sleep disorders, motor sleep disorders (including night terrors, sleep paralysis, sleepwalking, restless leg symptoms, sleep-related eating behaviors, etc.) and non-motor abnormal sleep disorders (including moaning, molars, Dream talk, etc.) is a 
neuro motor dysfunction, which is closely related to the types of neurodevelopment and nervous system activity. It may suggest that only-child families may pay more attention to eugenics and better parenting, and are superior to non-only children in terms of nutrition intake, lifestyle training, and parenting styles. Only children can reduce some of their sleep disturbances. In addition, this study found that the scores of sleepiness factors for only children are significantly higher than those of non-only children, that is, only children have more sleepiness than non-only children. Drowsiness manifests as excessive sleep, which is often related to psychological factors. At present, it is difficult to explain the reasons for the above differences, and further research is needed. Mental disorders for different demographic groups the analysis of the situation found that the introverted personality and personality shift factors of the urban population were significantly higher than those of the rural population that is, the urban population had more problems with personality. Related research shows that the environment Shaping personality traits. The urban-rural differences in personality traits are mainly related to the different cultural and economic environments in urban and rural areas. The intensified social competition and increased living pressure in cities can induce anxiety and depression, increase aggression and lack of self-confidence May lead to social fraud, sexual crime, and induce personality mutation [35-36]; People's life circles are relatively narrow, which is likely to cause individuals to lack social support, avoid reality, and eventually induce personality problems. The scores of various factors of the only child's mental disorders are significantly lower than those of the non-single child, indicating that the only child's mental health is better, which may be related to the family environment of the only child, the educational level of the parents, and the parenting style. Married people's mental disorder scores are significantly higher than those who are unmarried, that is, married people have a poorer mental health. Married people are generally older and their mental and physical functions are in a decline period; It is often the backbone of various industries that bear more work burdens and pressures, and at the same time bear the tasks of supporting the elderly, handling husbandwife relationships, and raising children, which easily puts married people in a chronic stress state and induces various mental problems.

\subsection{Relationship Between Sleep Quality and Mental Disorders in Pakistani}

This study found that there was a significant positive correlation between sleep quality and mental disorders in Pakistani. A regression analysis of the factors affecting mental disorders in Pakistan shows that factors of sleep problems can explain $38.8 \%$, Has a significant predictive effect on mental disorders, and the results are similar to a large number of existing studies. Previous studies have suggested that long-term sleep disorders can damage cognitive and social functions, increase behavioral problems and alcohol abuse, and cause individuals to feel despair and suicidal thoughts; increased susceptibility to adverse stimuli, and easier Damage from external stress can greatly increase an individual's risk of suffering from various mental disorders. 


\section{Conclusion}

In summary, this study found that there are some differences in sleep quality and mental disorders in different demographics, and sleep quality has a certain predictive effect on mental disorders. Therefore, the prevention of mental disorders must take into account different demographic groups and targeted development; at the same time, pay attention to the intervention of sleep problems, improve sleep quality, and reduce the occurrence of mental disorders.

\section{References}

1. Harsch IA. The effect of continuous positive airway pressure treatment on insulin sensitivity in patients with obstructive sleep apnoea syndrome and type 2diabetes. Respiration. 2004; 71(3), 252-259. https://doi.org/10.33513/jpst/1801-01

2. Jung SH, Park J. Effect of life stress on the sleeping disorder of university student. The Journal of the Korea Institute of Electronic Communication Sciences. 2013; 8(2), 345-353. https://doi. org/10.13067/jkiecs.2013.8.2.345

3. Yang J, Sadof C. Variation in the life history of the Citrus Mealybug parasitoid (Leptomastixdactylopii) Hymnoptera: Encyrtidae) on three varieties of Coleus blumei. Environment Entomology. 1997; 26, 978-82. https://doi. org/10.1093/ee/26.4.978

4. Comella CL, Nardine TM, Diederich NJ, Stebbins GT. Sleep-related violence, injury, and REM sleep behavior disorder in Parkinson's disease. Neurology. 1998; 51(2), 526-529. https://doi. org/10.1212/wnl.51.2.526

5. Ancoli-Israel S, Ayalon L, Salzman C. Sleep in the elderly: normal variations and common sleep disorders. Harvard Review of Psychiatry. 2008; 16(5), 279-286. https://doi. org/10.1080/10673220802432210

6. Ram S, Seirawan H, Kumar SK, Clark GT. Prevalence and impact of sleep disorders and sleep habits in the United States. Sleep and Breathing. 2010; 14(1), 63-70. https://doi.org/10.1007/ s11325-009-0281-3

7. Gillin JC. Are sleep disturbances risk factors for anxiety, depressive and addictive disorders? Acta Psychiatrica Scandinavica. 1998; 98, 39-43. https://doi.org/10.1111/j.1600-0447.1998. tb05965

8. Mindell JA, Owens JA, Carskadon MA. Developmental features of sleep. Child and Adolescent Psychiatric Clinics of North America. 1999; 8(4), 695-725. https://doi.org/10.1891/ 9780826106582.0002

9. Lakshminarayana Tadimeti MD, Caruana-Montaldo B, Wallace B, Mendelson MD. Sleep latency and duration estimates among sleep disorder patients: variability as a function of sleep disorder diagnosis, sleep history, and psychological characteristics. Sleep. 2000; 23(1), 1. https:// doi.org/10.1093/sleep/23.1.1d

10. Åkerstedt T, Wright KP. Sleep loss and fatigue in shift work and shift work disorder. Sleep Medicine Clinics. 2009; 4(2), 257-271. https://doi.org/10.1016/j.jsmc.2009.03.001

11. Prinz PN, Vitiello MV, Raskind MA, Thorpy MJ. Sleep disorders and aging. New England Journal of Medicine. 1990; 323(8), 520-526. https://doi.org/10.1037/10233-023

12. O’Brien LM, Ivanenko A, Crabtree VM, Holbrook CR, Bruner JL, Klaus CJ, Gozal D. Sleep disturbances in children with attention deficit hyperactivity disorder. Pediatric Research. 2003; 54(2), 237. https://doi.org/10.1016/j.sleep.2015.02.174 
13. Schenck CH, Bundlie SR, Patterson AL, Mahowald MW. Rapid eye movement sleeps behavior disorder: a treatable parasomnia affecting older adults. JAMA. 1987; 257(13), 1786-1789. https://doi.org/10.1001/jama.1987.03390130104038

14. Peppard PE, Szklo-Coxe M, Hla KM, Young T. Longitudinal association of sleep-related breathing disorder and depression. Archives of Internal Medicine. 2006; 166(16), 1709-1715. https://doi.org/10.1001/archinte.166.16.1709

15. Ford DE, Kamerow DB. Epidemiologic study of sleep disturbances and psychiatric disorders: an opportunity for prevention? JAMA. 1989; 262(11), 1479-1484. https://doi.org/10.1001/ jama.1989.03430110069030

16. Ford DE, Kamerow DB. Psychiatric disorders associated with circadian rhythm disturbances? 2005. https://doi.org/10.1002/0471751723.ch52

17. dos Santos AB, Barreto GE, Kohlmeier KA. Treatment of sleeping disorders should be considered in clinical management of Parkinson's disease. Frontiers in Aging Neuroscience. 2014; 6, 273. https://doi.org/10.3389/fnagi.2014.00273

18. Onofrj M, Luciano AL, Thomas A, Iacono D, d'Andreamatteo G. Mirtazapine induces REM sleep behavior disorder (RBD) in Parkinsonism. Neurology. 2003; 60(1), 113-115. https://doi. org/10.1212/01.wnl.0000042084.03066.c0

19. Kodak T, Piazza CC. Assessment and behavioral treatment of feeding and sleeping disorders in children with autism spectrum disorders. Child and Adolescent Psychiatric Clinics of North America. 2008; 17(4), 887-905. https://doi.org/10.1007/978-1-4614-4788-7_119

20. Crabtree VM, Ivanenko A, O’Brien LM, Gozal D. Periodic limb movement disorder of sleep in children. Journal of Sleep Research. 2003; 12(1), 73-81. https://doi.org/10.1093/sleep/zsw063

21. Papadimitriou GN, Linkowski P. Sleep disturbance in anxiety disorders. International Review of Psychiatry. 2005; 17(4), 229-236. https://doi.org/10.1080/09540260500104524

22. Abdulghani HM, Alrowais NA, Bin-Saad NS, Al-Subaie NM, Haji AM, Alhaqwi AI. Sleep disorder among medical students: relationship to their academic performance. Medical Teacher. 2012; 34(sup1), S37-S41. https://doi.org/10.3109/0142159x.2012.656749

23. Gruber R, Sadeh AVI, Raviv A. Instability of sleep patterns in children with attention-deficit/ hyperactivity disorder. Journal of the American Academy of Child \& Adolescent Psychiatry. 2000; 39(4), 495-501. https://doi.org/10.1046/j.1467-0658.2000.00093-20

24. Owens J. Classification and epidemiology of childhood sleep disorders. Primary Care: Clinics in Office Practice. 2008; 35(3), 533-546. https://doi.org/10.1016/j.jsmc.2007.05.009

25. Stein MB, Chartier M, Walker JR. Sleep in non depressed patients with panic disorder: I. Systematic assessment of subjective sleep quality and sleep disturbance. Sleep. 1993; 16(8), 724726. https://doi.org/10.1093/sleep/16.8.724

26. Thiedke CC. Sleep disorders and sleep problems in childhood. American Family Physician. 2001; 63(2), 277-287. https://doi.org/10.1201/b14948-4

27. Ancoli-Israel S. Sleep and its disorders in aging populations. Sleep Medicine. 2009; 10, S7-S11. https://doi.org/10.1016/j.sleep.2009.07.004

28. O’Brien LM, Holbrook CR, Mervis CB, Klaus CJ, Bruner JL, Raffield TJ, Hume BC. Sleep and neurobehavioral characteristics of 5-to 7-year-old children with parentally reported symptoms of attention-deficit/hyperactivity disorder. Pediatrics. 2003; 111(3), 554-563. https://doi. org/10.1542/peds.111.3.554

29. Tan A, Salgado M, Fahn S. Rapid eye movement sleep behavior disorder preceding Parkinson's disease with therapeutic response to levodopa. Movement Disorders: Official Journal of the Movement Disorder Society. 1996; 11(2), 214-216. https://doi.org/10.1002/mds.870110216 
30. Smith E. Child behavior and quality of life before and after tonsillotomy versus tonsillectomy. International Journal of Pediatric Otorhinolaryngology. 2009; 87(7), 1254-1262. https://doi. org/10.1016/j.ijporl.2009.05.015

31. Moldofsky H. Fibromyalgia, sleep disorder and chronic fatigue syndrome. Chronic Fatigue Syndrome. 1993; 262-271. https://doi.org/10.7748/ns.7.35.17.s40

32. Okawa M, Mishima K, Nanami T, Shimizu T, Iijima S, Hishikawa Y, Takahashi K. Vitamin Bl2 treatment for sleep-wake rhythm disorders. Sleep. 1990; 13(1), 15-23. https://doi.org/10.1093/ sleep/13.1.15

33. Ross RJ, Ball WA, Dinges DF, Kribbs NB, Morrison AR, Silver SM, Mulvaney FD. Motor dysfunction during sleep in posttraumatic stress disorder. Sleep. 1994; 17(8), 723-732. https:// doi.org/10.1093/sleep/17.8.723

34. Kavey NB, Blitzer A, Gidro-Frank S, Korstanje K. Sleeping position and sleep apnea syndrome. American Journal of Otolaryngology. 1985; 6(5), 373-377. https://doi.org/10.1016/ s0196-0709(85)80015-6

35. Sahota PK, Jain SS, Dhand R. Sleep disorders in pregnancy. Current Opinion in Pulmonary Medicine. 2003; 9(6), 477-483. https://doi.org/10.1016/b978-0-12-384911-3.00010-5

36. Boeve BF, Silber MH, Ferman TJ. REM sleep behavior disorder in Parkinson's disease and dementia with Lewy bodies. Journal of Geriatric Psychiatry and Neurology. 2004; 17(3), 146157. https://doi.org/10.1177/0891988704267465 